\title{
Wind Resource Characterization in the Arabian Peninsula
}

\author{
Chak Man Andrew Yip ${ }^{\mathrm{a}, *}$, Udaya Bhaskar Gunturu ${ }^{\mathrm{a}}$, Georgiy L. Stenchikov ${ }^{\mathrm{a}}$ \\ ${ }^{a}$ King Abdullah University of Science and Technology, Thuwal 23955-6900, Saudi Arabia
}

\begin{abstract}
Wind energy is expected to contribute to alleviating the rise in energy demand in the Middle East that is driven by population growth and industrial development. However, variability and intermittency in the wind resource present significant challenges to grid integration of wind energy systems. These issues are rarely addressed in the literature of wind resource assessment in the Middle East due to sparse meteorological observations with varying record lengths. In this study, the wind field with consistent space-time resolution for over three decades at three hub heights $(50 \mathrm{~m}, 80 \mathrm{~m}, 140 \mathrm{~m})$ over the whole Arabian Peninsula is constructed using the Modern Era Retrospective-Analysis for Research and Applications (MERRA) dataset. The wind resource is assessed at a higher spatial resolution with metrics of temporal variations in the wind than in prior studies. Previously unrecognized locations of interest with high wind abundance and low variability and intermittency have been identified in this study and confirmed by recent on-site observations. In particular, the western mountains of Saudi Arabia experience more abundant wind resource than most Red Sea coastal areas. The wind resource is more variable in coastal areas along the Arabian Gulf than their Red Sea counterparts at a similar latitude. Persistent wind is found along the coast of the Arabian Gulf.
\end{abstract}

Keywords: Wind Energy, Variability, Intermittency, Middle East, Resource Assessment, Reanalysis

\section{1. Introduction}

The potential adverse impacts of climate change and energy insecurity have encouraged countries worldwide 25 towards adopting renewable energy as an integral 26 part of their future energy mix. Near-surface wind ${ }_{27}^{27}$ energy has the potential to power the world; it allows ${ }^{28}$ extracting energy at a rate of at least $400 \mathrm{TW}$ [1]. It ${ }^{29}$ is suggested that following a moderate wind energy 30 deployment plan by 2050 would delay the crossing ${ }^{31}$ of the $2{ }^{\circ} \mathrm{C}$ threshold for 1 to 6 years [2]. Wind 32 energy provides a viable alternative energy source to energy intensive countries such as China, where it is estimated to be sufficient to replace $23 \%$ of the electricity generated from coal [3]. In the Middle East and North Africa (MENA), population growth has led to increases in demand for fuel and electricity for air- 38 conditioning and desalination. Regional annual Total 39 Primary Energy Supply (TPES) increased by $14.9 \%$ to 40 800 millions Mtoe (million tonnes of oil equivalent) in ${ }^{41}$ 2010 compared to the TPES of 2007 [4]. These steady increases in domestic consumption of energy drive

\footnotetext{
*Corresponding author

Email address: andrew.yip@kaust.edu.sa (Chak Man Andrew Yip)
} $[4]$ energy has grown from $0.8 \mathrm{TWh}$ in 2008 to $1.6 \mathrm{TWh}$ in 2011 [4]. This growth has been the result of rising opportunity cost of oil and gas accompanied by an increase in urbanization and a rapid rise in domestic demand for energy. These expansions are evident in the countries' recent large-scale procurement of renewable energy systems to fulfill national renewable targets [5]. The surging interest in renewable energy calls for a better understanding of the spatial and temporal characteristics of the resource. This paper focuses on the wind energy resource, the most variable and intermittent source of renewable energy in the Arabian Peninsula.

There are two key challenges in assessing the wind resource in the Arabian Peninsula. Most of the observations available are sparse in space and inconsistent in time: spatially scattered observations with varying record lengths come from meteorological 
stations that are located mainly in clustered coastal 101 and inland settlements. Hourly wind speeds were 102 collected by 293 weather stations in the Peninsula 103 during our period of study from 1979 to 2013. Among 104 the stations, 42 collected data for at least half of the 105 time. Only 17 stations have observations available 106 for more than $80 \%$ of the record length [6]. Despite ${ }_{107}$ these challenges, Ansari et al. [7] constructed the 108 Saudi Arabian Wind Energy Atlas in 1986 using hourly 109 observations from 20 airport weather stations from 110 1970 to 1982 . They described diurnal and seasonal 111 variations of wind speed at measurement height at 112 these locations and mapped prevailing wind directions. 113 Rehman and Halawani [8] described diurnal, monthly, 114 and inter-annual wind speed variations at 10 weather 115 stations. Most of the studies focused on prominent 116 sites of assessment that are mainly coastal. A similar ${ }_{117}$ tendency is observed for the MENA region [9-11], 118 with the exception of Ohunakin et al. [12] where the 119 focus was inland. These analyses concentrated on 120 wind speed time series from meteorological stations 121 with different record periods. The wind resource is 122 frequently characterized by average wind speed or 123 wind power density (WPD) that is at measurement 124 height or is adjusted to hub height. Recent works have 125 attempted to study the spatial variation of the wind resource. Jervase and Al-Lawati [13] performed an areal analysis of wind resource abundance in Oman using the NASA Surface Meteorology and Solar Energy (SSE) Release 6.0 dataset with a spatial resolution of $1^{\circ}$ $\times 1^{\circ}$. Al-Yahyai and Charabi assessed wind resource in Oman using a nested ensemble numerical weather prediction (NWP) approach, where two global models were used as boundary conditions to drive two local area models. The wind abundance has been assessed at the scale of a country [14] and a city [15]. Moreover, Charabi et al. [16] demonstrated that NWP models 136 at $7 \mathrm{~km}$ are effective in resolving finer structures such as the sea breezes in this region. However, without well-formulated boundary conditions based on a long- ${ }^{137}$ term and spatially and temporally consistent dataset, an NWP model would not capture the impact of ${ }^{130}$ large-scale circulations such as the El Niño. Since ${ }_{140}$ these circulations are of low frequency, they have ${ }_{141}$ higher spectral power and, therefore, have a significant ${ }_{142}$ impact on the wind resource. Existing meteorological observations contain missing data due to handling 143 errors or malfunctioning of the instrument. These 144 observations are spatially sparse, for instance, located 145 mainly at airports and urban areas. These factors led to some potentially resource-rich regions being overlooked, which prevented prior studies in developing a comprehensive characterization of the wind resource for the entire Arabian Peninsula.
Moreover, previous resource characterizations have focused on average wind abundance and annual energy production estimates. Wind power variability and intermittency present significant challenges to grid integration of wind energy systems, as identified by wind integration studies in the United States [17]. Variability and intermittency have been considered, most commonly using tower measurements where data are limited in the spatial and temporal dimensions [18-20]. Rehman and Halawani [8] provided a wind persistence measure via auto-correlation and autoregression for ten weather stations. Rehman and Ahmad [21] presented a wind availability analysis for 5 coastal locations in Saudi Arabia in terms of frequency of wind speed within a specified interval. Wind speed time series from meteorological stations were fitted by Weibull distributions to investigate the monthly variation of wind speed and their changes with hub height in Saudi Arabia [22, 23] and Bahrain [24]. Ouarda et al. [25] fitted multiple distributions and assessed their goodness-of-fit with wind speed measurements in the United Arab Emirates (UAE). However, the variability and intermittency of the wind resource have not been studied in the entire Peninsular region.

The primary goal of this study is to overcome the limitation of sparse station observations with varying record lengths by constructing the wind field using a gridded reanalysis dataset with a multi-decadal record period to arrive at a characterization of wind variability and intermittency. We characterize the wind resource using metrics proposed in Gunturu and Schlosser [26] (United States), Cosseron et al. [27] (Europe), Fant and Gunturu [28] (South Africa), and Hallgren et al. [29] (Australia).

This work aims to answer the following questions:

- What methodology can be used to assess the wind energy resource in a region where observational data are sparse and non-concurrent? (section 2)

- Where are the areas with wind power potential that were not previously located due to lack of observations? (section 3.1)

- How do wind variability and intermittency differ in spatial distributions from conventional metrics of resource abundance? (sections 3.2 and 3.3)

In the following sections, we explore regional wind resource and compare our results with results from prior studies. We first describe wind resource abundance as characterized by the median WPD. Our wind 
field reconstruction shows a qualitative agreement with 195 previous studies. We then describe the regional wind 196 resource using metrics of variability and intermittency. 197

\section{Material and Methods}

\subsection{Data}

The spatial domain of interest spans the Arabian 204 Peninsula bounded between $10^{\circ} \mathrm{N}$ and $35^{\circ} \mathrm{N}$ in latitude 205 and $35^{\circ} \mathrm{E}$ and $60^{\circ} \mathrm{E}$ in longitude. This spatial extent 206 allows investigation of the Red Sea, the Gulf of Aden, 207 the Arabian Gulf, and part of the Arabian Sea along with inland areas.

The WPD field is reconstructed using the Modern Era Retrospective-Analysis for Research and Applications (MERRA) dataset. MERRA is a reanalysis conducted by the Global Modeling and Assimilation Office (GMAO) at NASA using the Goddard Earth Observing System Version 5 (GEOS-5). GEOS-5 is a general circulation model (GCM) used within a data assimilation system where satellite and surface observations are utilized [30]. The dataset has a spatial resolution of $0.5^{\circ}$ (latitude) $\times 0.67^{\circ}$ (longitude) and hourly output is available. For this study, a record period from January 1, 1979 midnight (UTC) to January 1, 2014 midnight (UTC) is chosen. This temporal range enables studying of wind variation over different time scales from hours to decades. The spatial coverage of the dataset provides an opportunity to understand the regional wind patterns, those that coarse observations cannot address.

Wind speed and WPD are two primary variables in ${ }^{225}$ wind resource assessments. Wind speed at the turbine ${ }^{226}$ hub height is calculated using the similarity theory for 227 the surface layer in which the turbine submerges [31]. ${ }^{228}$ Wind speed is computed as

$$
u(z)=\frac{u_{*}}{\kappa} \ln \frac{z-d}{z_{0}}-\psi
$$

where $z$ is the turbine hub height [31]. $u_{*}=$ $\left[\left(\overline{u^{\prime} w^{\prime}}\right)^{2}+\left(\overline{v^{\prime} w^{\prime}}\right)^{2}\right]^{1 / 4}$ is the friction velocity, defined ${ }_{233}$ with the surface kinematic momentum fluxes in $\mathrm{x}$ and 234 y directions. $\kappa=0.41$ is a standard accepted value of 235 the von Kármán constant [32]. $d$ is the displacement 236 height that gives the vertical displacement of the entire ${ }_{237}$ flow regime over areas densely covered with obstacles. 238 Roughness length $z_{0}$ defines the height that the wind ${ }_{239}$ speed is assumed to vanish near the ground. The 240 parameter $\psi$ depends on the stability of the boundary 241 layer. A neutral boundary layer is assumed, thus 242 $\psi=0 . \quad$ Neutral stratification assumes negligible effects of external heating on the vertical distribution of temperature. Although neutral stratification is widely assumed in previous studies of wind resource assessment to adjust wind speed to hub height from measurement height, the neutral boundary layer may not occur in the presence of surface heating [33]. Intense surface heating causes warm air near the surface to rise and create turbulence as in the case of an unstable boundary layer. It implies a smaller change in wind speed with height than in a neutral case. WPD is the wind power available per unit swept area of a turbine defined as

$$
\mathrm{WPD}=\frac{1}{2} \rho u^{3}
$$

where $\rho$ is the air density and $u$ is the wind speed [31]. The fields for calculating wind speed and WPD at hub height have been extracted from the MERRA 2D surface turbulent flux diagnostics available at a single level at the top of the surface layer. Specifically, momentum roughness length (Z0M), friction velocity (USTAR), surface air density (RHOA), and displacement height (DISPH) are extracted from the dataset for the computation. Wind speed and WPD have been computed at all hourly time-steps at $50 \mathrm{~m}, 80 \mathrm{~m}$, and $140 \mathrm{~m}$ corresponding to the typical hub heights of the three generations of wind turbines. Most prior studies in the region did not consider terrain and local conditions when adjusting wind speed to hub height (e.g., [34]), where the effects of wind shear were demonstrated to be significant in power generation [35]. The WPD provides a proxy to wind power resource that is independent of a wind energy system's specification. It combines the contributions of both wind speed and air density in illustrating the physical limit of wind power potential.

\subsection{Metrics}

Prior studies of the wind energy resource in the Arabian Peninsula were mostly concerned with the abundance of the wind resource in terms of average wind speed or annual energy production estimates. Variability and intermittency have not been investigated comprehensively for this region. The understanding of these temporal characteristics is essential for grid integration to pave the way for wind energy to become part of a larger generation network contributing to the generation of base-load electricity. Therefore, we consider three essential metrics in evaluating the wind energy resource: abundance, variability, and intermittency. 
Abundance is the amount of wind energy available. ${ }^{283}$ It is conventionally measured by time-averaged wind 284 speed $(\bar{u})$ or time-averaged WPD, which takes the 285 form of

$$
\bar{x}=\frac{1}{T} \int_{0}^{T} x \mathrm{dt},
$$

where $x$ is the instantaneous wind speed or wind power density, and $T$ is the length of the record period. Timeaveraged WPD and wind speed are used to compare with results from prior studies in the region. For each grid cell in the domain, the hourly wind power density field is used to compute the average WPD over the record period.

$$
\bar{p}=\frac{1}{n} \sum_{t=1}^{n} p_{\mathrm{t}},
$$
where $p_{\mathrm{t}}$ is the average WPD at each hour $(t)$ and $n$ is 295 the total number of time-steps in the record period. In 296 addition, we compute the median WPD, $p_{\text {med, }}$ which ${ }^{297}$ is the value lying at the midpoint of a frequency ${ }_{298}$ distribution of the time series at each grid point such ${ }_{299}$ that there is an equal probability to be above or below it. The median is a metric robust to extreme samples and hence is a better characterization of central tendency than the mean for skewed distributions such as those of wind speed and WPD. The $p_{\text {med }}$ is used to characterize the wind regimes in the further analysis: regime I where $p_{\text {med }} \geq 67 \mathrm{~W} \mathrm{~m}^{-2}$, regime II where ${ }^{302}$ $46 \mathrm{~W} \mathrm{~m}^{-2} \leq p_{\text {med }}<67 \mathrm{~W} \mathrm{~m}^{-2}$, and regime III where ${ }^{303}$ $p_{\text {med }}<46 \mathrm{~W} \mathrm{~m}^{-2}$. The three regimes correspond to ${ }^{304}$ values separated by the $33 \mathrm{rd}$ and 67 th percentiles of 305 the median WPDs for all grid cells in the domain. ${ }^{306}$ This classification gives an indication of the relative ${ }_{307}$ spatial abundance of the wind resource in the region. ${ }_{308}$ Variability characterizes the fluctuations of the wind 309 energy resource at a given location. It is measured by 310 the robust coefficient of variation ( $\mathrm{rCV}$ ) of WPD [26], ${ }^{311}$ computed as follows for each cell:

$$
\mathrm{rCV}=\frac{\operatorname{median}\left(\left|p-p_{\text {med }}\right|\right)}{p_{\text {med }}} .
$$

The rCV provides a dimensionless measure of variability across the spatial domain. High rCV indicates highly variable wind resource, thus less desirable for operation.

Intermittency is defined by availability and persistence 322 of the wind resource. Availability is the fraction of time 323 over a time series when the WPD exceeds a threshold 324 of $200 \mathrm{~W} \mathrm{~m}^{-2}$. The threshold has been chosen keeping in mind the $300 \mathrm{~W} \mathrm{~m}^{-2}$ threshold (Wind Class 3) in filtering sites for commercial scale power production in the Regional Energy Deployment System (ReEDS) model of the National Renewable Energy Laboratory (NREL) [36]. A lower threshold of $200 \mathrm{~W} \mathrm{~m}^{-2}$ (Wind Class 2) is chosen in light of recent developments in low-wind turbines which render conventionally lowwind areas viable for energy applications. Availability $(A)$ is computed following [26],

$$
\begin{gathered}
A=\frac{1}{n} \sum_{t=1}^{n} \tau\left(p_{\mathrm{t}}\right), \\
\tau\left(p_{\mathrm{t}}\right)=\left\{\begin{array}{lr}
1, & p_{\mathrm{t}}>200 \mathrm{~W} \mathrm{~m}^{-2} \\
0, & \text { otherwise }
\end{array}\right.
\end{gathered}
$$

$\tau\left(p_{\mathrm{t}}\right)$ records the events when $p_{\mathrm{t}}$ is greater than the threshold. Persistence reflects the steadiness over time in wind power generation above a given threshold. Episode length is defined as the duration of consecutive time steps when $p_{\mathrm{t}}$ is above the threshold.

Persistence is measured by the median episode length (MEL). The median length of wind episodes is the median length of all recorded continuous periods when WPD is above the threshold [26],

$$
\mathrm{MEL}=\operatorname{median}\left[\tau\left(p_{\mathrm{t}}\right)\right] .
$$

It should be noted that intermittency concerns the statistics of threshold-crossing of the WPD while variability measures the fluctuation of the WPD in magnitude. This distinction was elaborated in Gunturu and Schlosser [26].

The present study aims at identifying regional features of wind resource while finer local characteristics and circulations could not be represented. Our analysis identifies regions for further down-scaling and micrositing assessment where models with finer resolutions in space and time are appropriate. Dynamical downscaling in the mountainous regions of the Arabian Peninsula would benefit from the use of Kalman filters, as it has shown improvements in NWP wind speed forecast in complex terrain [37]. Sub-hourly data would be needed to characterize wind intermittency at scales relevant to grid integration of individual wind farms, as illustrated in the Wind Integration National Dataset (WIND) Toolkit by NREL [38]. Prevalence of intense surface heating in the region requires proper parameterization of the stability of the boundary layer to better estimate the variation of wind speed with height during day-time. It is also important to validate 


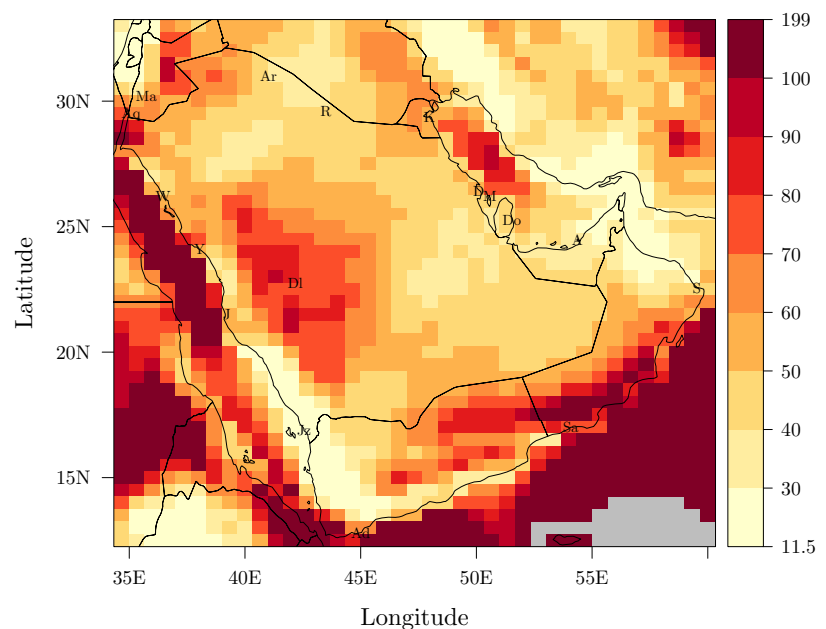

Figure 1: Median WPD $\left(\mathrm{W} \mathrm{m}^{-2}\right)$ computed at $50 \mathrm{~m}$ AGL using the wind fields reconstructed from the MERRA data. The color scale is uniform except for values beyond $100 \mathrm{~W} \mathrm{~m}^{-2}$ and below $30 \mathrm{~W} \mathrm{~m}^{-2}$. Large extreme values beyond the 98-percentile in the spatial domain are masked in grey. Selected locations of prior studies (table A.1) are shown.

model results with current in situ measurements at different hub heights, such as the measurements taken by K.A.CARE in Saudi Arabia [39].

\section{Results}

\subsection{Abundance}

Near-surface wind resource over the Arabian Peninsula varies due to its diverse topographical features. We discuss the wind resource over this vast area by categorizing the spatial domain into three regimes based on the median WPD (fig. 1). The three wind regimes are illustrated in fig. 2 .

\subsubsection{Regime I (relatively abundant)}

The Arabian Peninsula shows a varied abundance of the near-surface wind resource spatially. Regime I shows the most abundant wind resource in the region with median WPD above $67 \mathrm{~W} \mathrm{~m}^{-2}$. Offshore regions have the most abundant wind resource. Among the onshore locations, the Hejaz Mountains east of Jeddah in Saudi Arabia, the southern coast of Oman, and eastern Yemen show a relatively high abundance of wind resource. The mountainous coastline along the Gulf of Aqaba and central Jordan also have moderately abundant wind resource. These regions show a comparable spatial distribution of average and median WPD and the average WPD is about twice the

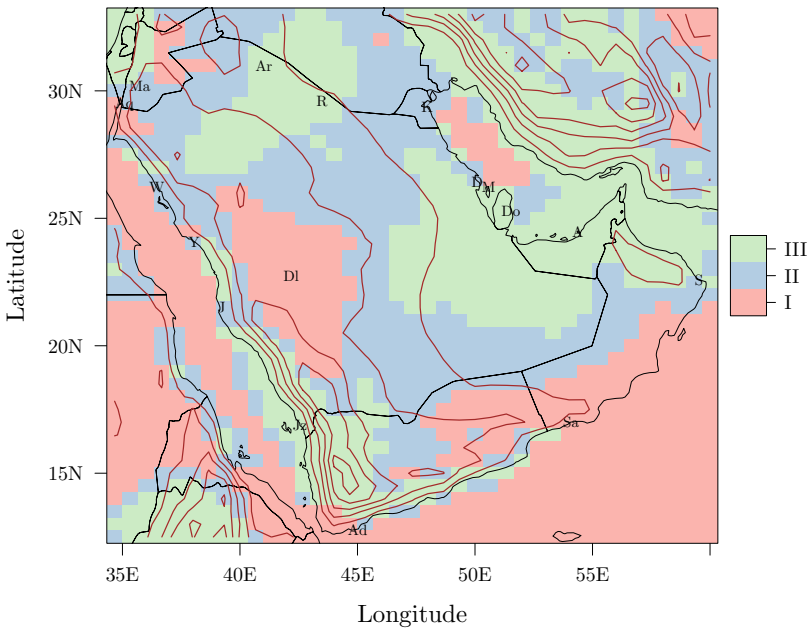

Figure 2: Categorized median WPD (fig. 1) at $50 \mathrm{~m}$ AGL into three regimes: regime I where median WPD is above $67 \mathrm{Wm}^{-2}$, regime II where median WPD is from $46 \mathrm{~W} \mathrm{~m}^{-2}$ to $67 \mathrm{Wm}^{-2}$, and regime III where median WPD is below $46 \mathrm{~W} \mathrm{~m}^{-2}$. Elevation contours at $400 \mathrm{~m}$ intervals are drawn using elevation data from MERRA. Selected locations of prior studies (table A.1) are shown.

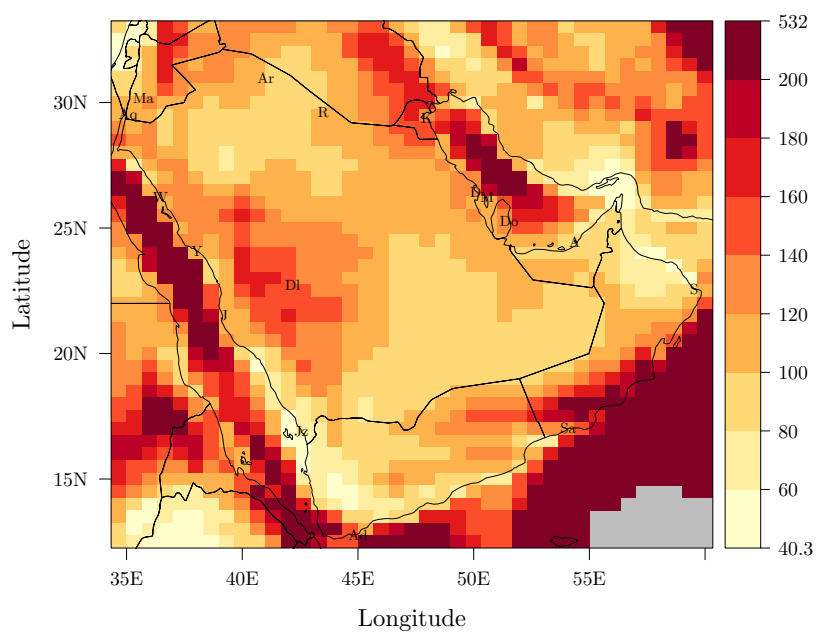

Figure 3: Average WPD $\left(\mathrm{W} \mathrm{m}^{-2}\right)$ computed at $50 \mathrm{~m}$ AGL using the wind fields reconstructed from the MERRA data. The color scale is uniform except for values beyond $200 \mathrm{~W} \mathrm{~m}^{-2}$ and below $60 \mathrm{~W} \mathrm{~m}^{-2}$. Large extreme values beyond the 98-percentile in the spatial domain are masked in grey. Selected locations of prior studies (table A.1) are shown. 
median, illustrating a positively skewed distribution 402 (fig. A.2). One exception is along the coast of the Gulf 403 of Aqaba, where the average and median WPD are 404 close, leading to a less skewed distribution.

The abundance of the wind resource is illustrated in average WPD (fig. 3). A map of average wind speed is also included for reference and comparison with prior studies where WPD is not available (fig. A.3). The East of the Hejaz and Asir mountains in Saudi Arabia 409 has average WPD of $143 \mathrm{~W} \mathrm{~m}^{-2}$. This is confirmed by recent meteorological measurements from 1998 to 2002 at Dhulum with average WPD of $186 \mathrm{~W} \mathrm{~m}^{-2}{ }^{411}$ at $40 \mathrm{~m}$ AGL [40]. Before the use of reanalysis, wind resource assessments relied on data collected at meteorological stations and compared among known locations. The consensus from earlier studies has been that coastal areas possess more abundant wind 416 resources (e.g., [41]). Our discovery of higher wind 417 resources away from the coast points to the need for 418 more in situ observations at locations indicated in this 419 study.

Bahrain and Qatar show average WPD (wind speed) of around $119 \mathrm{~W} \mathrm{~m}^{-2}\left(4.63 \mathrm{~m} \mathrm{~s}^{-1}\right)$ and $139 \mathrm{~W} \mathrm{~m}^{-2}$ $\left(4.71 \mathrm{~m} \mathrm{~s}^{-1}\right)$ respectively. A prior study [24] shows an average wind speed of $8.65 \mathrm{~ms}^{-1}$ at $60 \mathrm{~m}$ AGL extrapolated from hourly observations at $10 \mathrm{~m}$ AGL at Bahrain International Airport from 2003 to 2005. These observations point to the need for further investigations to better understand the disparity between the median and average WPD shown in Bahrain and Qatar where the ocean strongly influences circulation over the island and the peninsula.

Along the Oman coast, our results show an average WPD of about $197 \mathrm{~W} \mathrm{~m}^{-2}$ for southern coast and $85.8 \mathrm{~W} \mathrm{~m}^{-2}$ near Sur. Meteorological observations reported at Thumrait, Sur, Masirah, and Marmul, show average WPD of $230,194,165$, and $109 \mathrm{~W} \mathrm{~m}^{-2}{ }^{436}$ at $10 \mathrm{~m} \mathrm{AGL} \mathrm{[42].} \mathrm{Further} \mathrm{investigations} \mathrm{into} \mathrm{the}$ long-term time-series would help reveal climatological ${ }_{438}$ differences in the two sub-regions.

In eastern Yemen around the Hadramaut Mountains, we find an average WPD (wind speed) of about $110 \mathrm{~W} \mathrm{~m}^{-2}$. The region surrounding Aden shows an average WPD of about $105 \mathrm{~W} \mathrm{~m}^{-2}\left(4.75 \mathrm{~m} \mathrm{~s}^{-1}\right)$, where the wind speed decreases further eastward. A prior study [43] using five years of meteorological observations from the airport at Aden shows an average wind speed of $4.5 \mathrm{~m} \mathrm{~s}^{-1}$ at $10 \mathrm{~m}$ AGL. The more abundant wind resource appears in the west of Aden, where future in situ observations would benefit from further studies into the local resource characteristics. Along the coast of the Gulf of Aqaba, the average ${ }_{452}$
WPD is around $105 \mathrm{~W} \mathrm{~m}^{-2}$. In central Jordan, average WPD is found to be $176 \mathrm{~W} \mathrm{~m}^{-2}$. This finding seems to deviate from prior observations where the wind resource is more abundant in the southwestern area. In particular, Fujaij shows an average WPD of around $91.6 \mathrm{~W} \mathrm{~m}^{-2}\left(4.3 \mathrm{~ms}^{-1}\right)$, where the annual average wind speed of $6.88 \mathrm{~ms}^{-1}$ was reported [44].

\subsubsection{Regime II (moderately abundant)}

Regime II shows areas with a moderately rich wind resource of median WPD between 46 and $67 \mathrm{~W} \mathrm{~m}^{-2}$. It includes the northern coast of the Red Sea, the coast of the Arabian Gulf, the areas west of Riyadh and along the borders of Saudi Arabia with Yemen and Oman, and northwestern Kuwait.

The northern Arabian coast of the Red Sea has been popular for wind resource studies due to long-standing meteorological measurements at major settlements. Our results show that the surroundings of Yanbu have an average WPD around $106 \mathrm{~W} \mathrm{~m}^{-2}$, close to the observed $134 \mathrm{~W} \mathrm{~m}^{-2}$ [40]. Our results indicate that a more abundant wind resource is present within $100 \mathrm{~km}$ of the meteorological stations. Northwest of Yanbu shows a higher wind average WPD of around $138 \mathrm{~W} \mathrm{~m}^{-2}$. Comparable wind abundance can also be found in the mountains further north of Yanbu and along the coast of the Red Sea northwest of Yanbu. This analysis identifies coastal sites beyond those discussed and observed in prior studies (i.e., Rehman and Ahmad [21]).

The coast of the Arabian Gulf illustrates a highly positively skewed distribution of WPD where the average value is about three times the median, indicating a potentially high variability in wind power previously not reported in the literature. The average WPD near Dhahran is shown to be around $136 \mathrm{~W} \mathrm{~m}^{-2}$, close to the observed $154 \mathrm{~W} \mathrm{~m}^{-2}$ [40].

Kuwait also shows a highly positively skewed distribution in WPD as illustrated by the difference between the median (fig. 1) and the average WPD (fig. 3). Northwestern Kuwait has an average WPD of around $164 \mathrm{~W} \mathrm{~m}^{-2}$, where southern Kuwait shows an average WPD of around $147 \mathrm{~W} \mathrm{~m}^{-2}$. A prior study shows an average WPD at $30 \mathrm{~m}$ AGL at Umm Omara (northwest) and Al-Wafra (south) to be $271 \mathrm{~W} \mathrm{~m}^{-2}$ and $273 \mathrm{~W} \mathrm{~m}^{-2}$ respectively. These discrepancies could arise from the choice of a constant exponent of $1 / 7$ when adjusting the wind speed from $10 \mathrm{~m}$ AGL

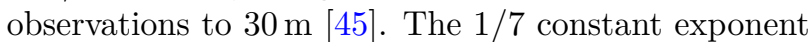
has been a popular choice in the wind resource assessment literature in extrapolating wind speed to hub height and deemed inappropriate for domains with 


\subsubsection{Effects of variation of hub height}

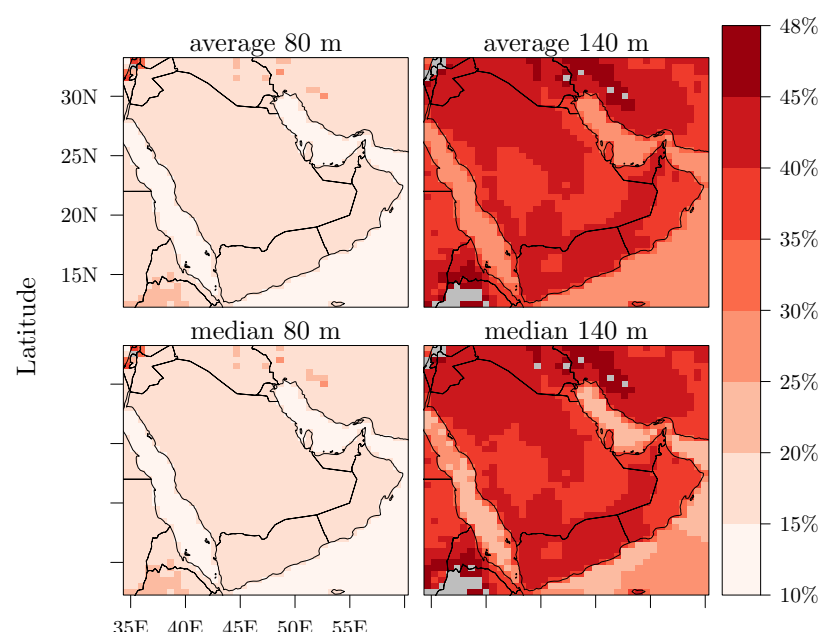

$\begin{array}{lllll}35 \mathrm{E} & 40 \mathrm{E} & 45 \mathrm{E} & 50 \mathrm{E} & 55 \mathrm{E}\end{array}$

Longitude

Figure 4: Changes of median WPD (fig. 1) and average WPD (fig. 3) at $80 \mathrm{~m}$ and $140 \mathrm{~m}$ from those at $50 \mathrm{~m}$ AGL. Large extreme values beyond the 98 -percentile in the spatial domain are masked in grey. The color scale is uniform except for values 504 beyond $45 \%$.

complex surface characteristics [46]. This choice of the 480 aracteristics, leading to an overestimate of the wind ${ }_{482}$

\subsubsection{Regime III (least abundant)}

Regime III shows areas with the comparatively least ${ }^{487}$ wind resource in the region where median ${ }^{488}$ he east coast of Oman, and Abu

The southern Arabian coast of the Red Sea has an average WPD (wind speed) of around $70.4 \mathrm{~W} \mathrm{~m}^{-2}$ Jizan, where monthly average wind speed is between $3.8 \mathrm{~m} \mathrm{~s}^{-1}$ and $5.2 \mathrm{~m} \mathrm{~s}^{-1}$ [21]. The southern Yemen coast also shows comparable wind power density, with similar mountainous terrain along the coastline. Ueastern Oman and the UAE show low average $25,42]$.

The rate of change of average and median WPD with 507 altitude depends on the roughness length (fig. A.4). ${ }_{508}$ Roughness length defines the influence of surface 509 characteristics on wind power resource. Figure 4 shows 510 a general increase of WPD with altitude, much affected 511 by the varying terrain. Offshore locations show lower increase than onshore sites. These observations are consistent across average and median WPD. With increased hub height, both the magnitude and the frequency of higher wind power resource increase and shift the distribution to higher WPD values, making it less skewed. The rate of increase is proportionally consistent across the average and median WPD at the two altitudes.

\subsubsection{Comparison with Vestas' wind map over Saudi Arabia at $100 \mathrm{~m}$ AGL}

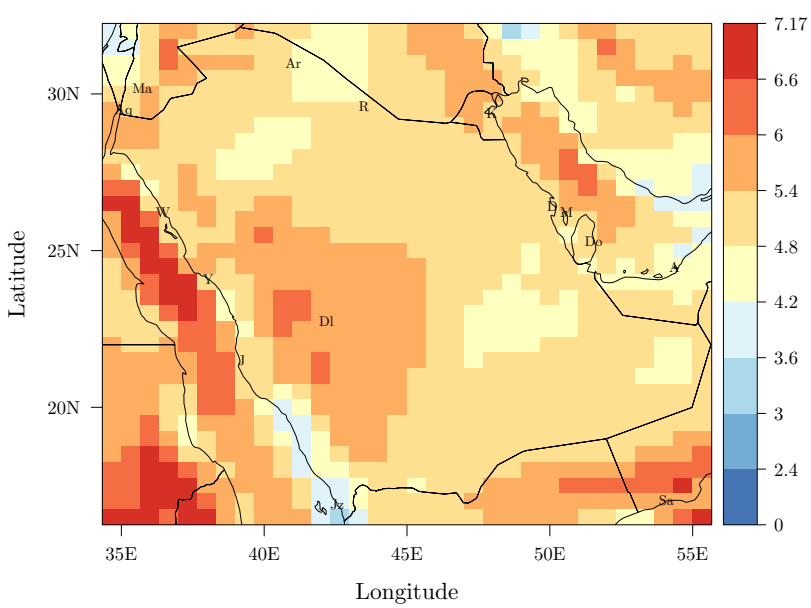

Figure 5: Average wind speed $\left(\mathrm{m} \mathrm{s}^{-1}\right)$ computed at $100 \mathrm{~m}$ AGL using the wind fields reconstructed from the MERRA data. The color scale is uniform except for values beyond $6.6 \mathrm{~m} \mathrm{~s}^{-1}$ and below $2.4 \mathrm{~m} \mathrm{~s}^{-1}$. Selected locations of prior studies (table A.1) are shown.

Figure 5 shows the annual average wind speed at $100 \mathrm{~m}$ AGL by our reconstruction and fig. 6 shows its comparison to Vestas' estimation. Vestas' wind speed map was calculated using the output from the Weather Research and Forecasting (WRF) model with a spatial resolution of $3 \mathrm{~km} \times 3 \mathrm{~km}$ and hourly temporal resolutions from 2000 to 2013 [47]. The wind speed estimate is available at the Renewable Resource Atlas at King Abdullah City for Atomic and Renewable Energy (K.A.CARE) in Saudi Arabia [39]. The model was driven by the boundary conditions from the National Center for Environmental Prediction (NCEP) Global Forecast System Analysis of $1^{\circ} \times 1^{\circ}$ spatial resolution and 6-hourly temporal resolution. Topography used in the Vestas model was obtained from the Moderate Resolution Imaging Spectroradiometer (MODIS) of $30^{\prime \prime} \times 30^{\prime \prime}$ spatial resolution. Figure 5 indicates relatively high average wind speed at the tip of the Gulf of Aqaba, north of Duba, west of Yanbu, south of Jeddah, and to the east of the Hejaz and Asir Mountains. Figure 6 


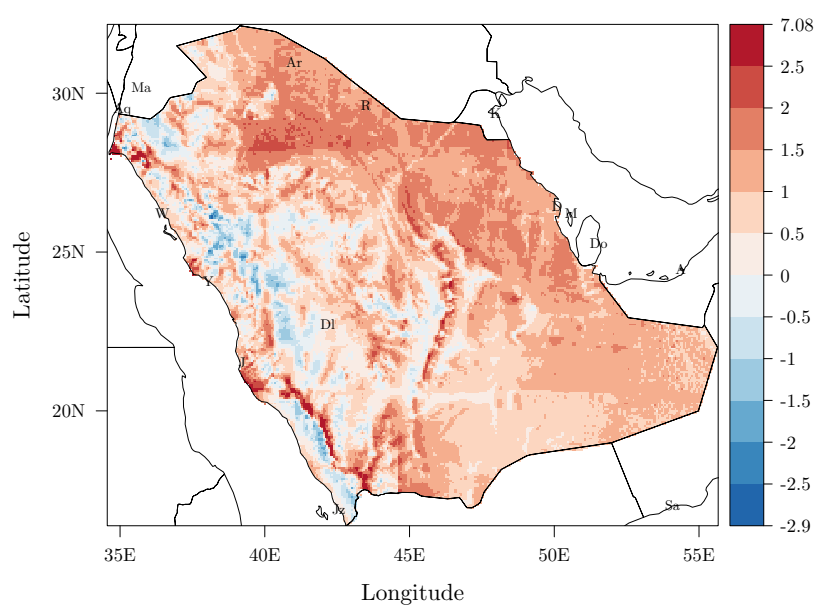

Figure 6: Differences in the average wind speed $\left(\mathrm{ms}^{-1}\right)$ at ${ }^{5}$ $100 \mathrm{~m}$ AGL between our calculation and that from estimation 557 of Vestas (Vestas - MERRA) are illustrated with a color scale 558 that is uniform except for values beyond $2.5 \mathrm{~m} \mathrm{~s}^{-1}$ and below ${ }_{559}$ $-2.5 \mathrm{~m} \mathrm{~s}^{-1}$. Selected locations of prior studies (table A.1) are shown. The MERRA dataset is regridded to $1 \mathrm{~km}$ resolution by nearest neighbor for illustration.

shows that the wind speed patterns of the two maps are qualitatively similar, with root-mean-square error 563 (RMSE) of $1.15 \mathrm{~m} \mathrm{~s}^{-1}$. However, at these identified high wind locations the Vestas' map holds higher values than from our reconstructions using MERRA, with the Vestas' average wind speed being $0.424 \mathrm{~m} \mathrm{~s}^{-1}$ higher on average. The area in the north near Arar and Rafha, and in the east near the coast of the Arabian Gulf show similar spatial patterns in wind speed with the Vestas' map, but higher values in general. This qualitative assessment reflects the higher spatial variability that is shown in the model with higher spatial resolution. A converse pattern is shown on the Vestas' map where there is a higher wind speed east of Najran than in the Empty Quarter. There is a higher wind speed shown to the west of the Hejaz Mountains where fine topographical features exist in the Vestas' map. It remains to investigate further these discrepancies and their relation to the models and assimilation schemes.

\subsubsection{Comparison with 3TIER's wind speed map at} $80 \mathrm{~m} A G L$

The average wind speed at $80 \mathrm{~m}$ AGL from our 565 reconstruction using the MERRA dataset is compared 566 with 3TIER's average wind speed map. The 3TIER 567 wind map is available with $5 \mathrm{~km}$ spatial resolution 568 hosted at the Global Atlas for Renewable Energy of the 569 International Renewable Energy Agency (IRENA) [48]. 570 The 3TIER's map uses over ten years of hourly data 571 generated from statistical and dynamical downscaling 572 where surface-atmosphere interactions are accounted for. The 3TIER wind speed estimates were validated with 229 NCEP-ADP stations in the Middle East and Africa, where only around 60 stations are in the Middle East [49]. The RMSE is $1.03 \mathrm{~m} \mathrm{~s}^{-1}$ between the annual average wind speed of station data and those from the model output in Africa and the Middle East. However, the data for the 3TIER map are not retrievable. There is also a lack of publicly available documentation on the creation of the dataset. Hence, the following discussion is not illustrated.

Our wind speed reconstruction and 3TIER's estimates are qualitatively similar. On the coast of the Red Sea, the two maps agree on the lower wind speed between the southern Red Sea and the mountains. Prominent wind patterns agree over the north, the east, and the south of Saudi Arabia, the UAE, Qatar, Kuwait, the eastern and the southern coasts of Oman, and Yemen. Known locations at Yanbu, Jeddah, and Al Qahma appear to show higher wind speed in the 3TIER map than in the MERRA reconstruction.

\subsection{Variability}

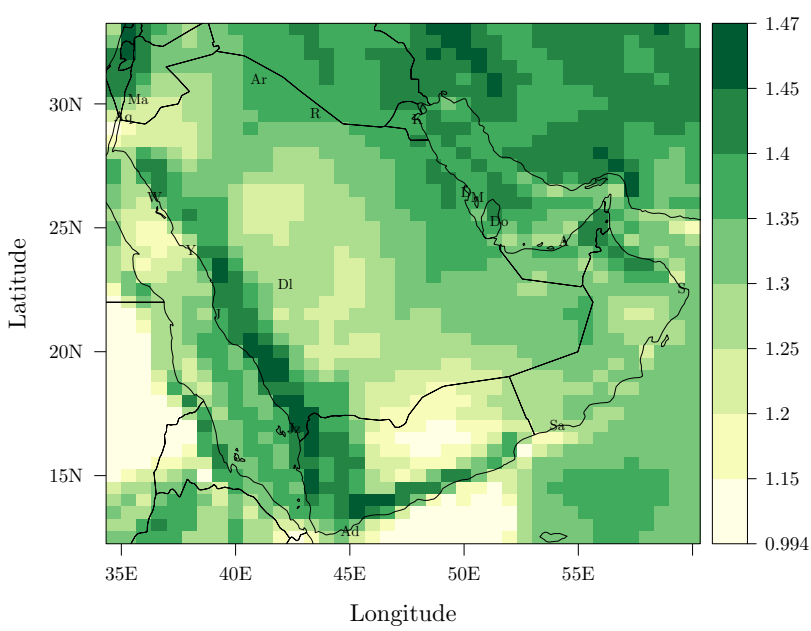

Figure 7: Robust coefficient of variation computed at $50 \mathrm{~m}$ AGL using the wind fields reconstructed from the MERRA data. The color scale is uniform except for values beyond 1.45 and below 1.15. Selected locations of prior studies (table A.1) are shown.

The robust coefficient of variation (fig. 7) measures the median deviation as a fraction of median WPD. A higher $\mathrm{rCV}$ indicates relatively higher variability at a location in WPD. Low variability reduces the output volatility and is favorable for power generation Figure 7 indicates that the sea-ward side of elevated areas shows greater variability than other sites in the spatial domain. Within the Regime I area, the inland face of the Hejaz and Asir Mountains shows relatively 
low variability. Similarly, the Hadramaut Mountains 601 in Yemen and the Wahiba Sands desert in eastern 602 Oman show relatively low variability in WPD. Along 603 the Gulf of Aqaba, the mountainous region also shows 604 relatively low variability. Within Regime II, both the coastlines of the Red Sea and the Arabian Gulf show higher variability than inland locations. However, the surroundings of Yanbu show only moderate variability. Changes in hub height lead to insignificant changes in variability (fig. A.5).

\subsection{Intermittency}

Intermittency is characterized by availability and persistence.

\subsubsection{Availability}

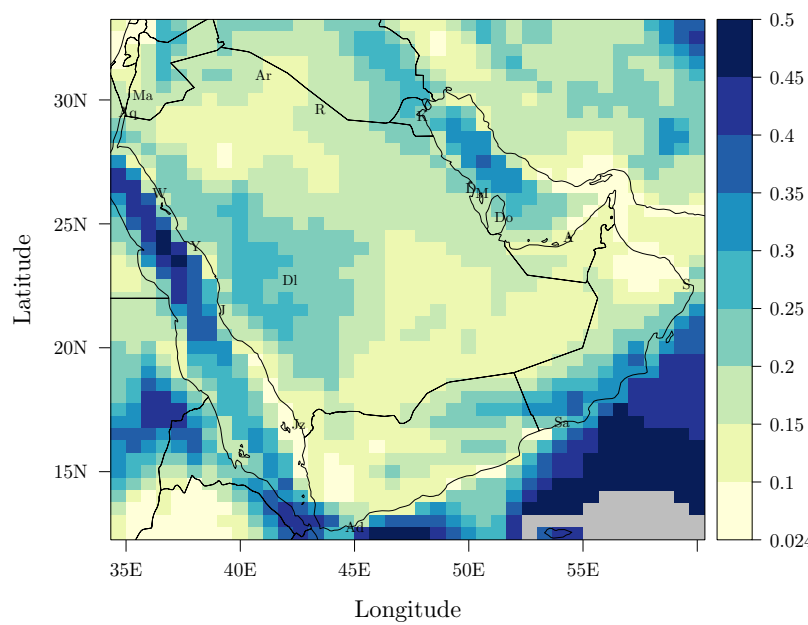

Figure 8: Availability of wind resource computed at $50 \mathrm{~m}$ AGL using the wind fields reconstructed from the MERRA data. The color scale is uniform except for values beyond 0.45 and below 0.1 . Large extreme values beyond the 98-percentile in the spatial domain are masked in grey. Selected locations of prior studies (table A.1) are shown.

Availability (fig. 8) measures the fraction of time when the wind power resource is above a given threshold (i.e., $200 \mathrm{~W} \mathrm{~m}^{-2}$ ). It represents the amount of time with meaningful power generation by a turbine. Most onshore locations have availability between $10 \%$ to $30 \%$, except for the low wind abundance areas in Yemen, northeast Oman, and along the southern coast of the Red Sea. Areas with abundant wind resource appear to have high availability. The western mountains in Saudi Arabia, the southern coast of Oman, the tip of the Gulf of Aden, and Kuwait show availability of around $25 \%$.

Figure 9 shows that an increase in hub height ${ }_{614}$ contributes to increased availability onshore due to 615 reduced effect of boundary layer friction on the wind by the surface. Increases in availability with hub height are most significant in regions with low wind abundance, except southern coastal Yemen.

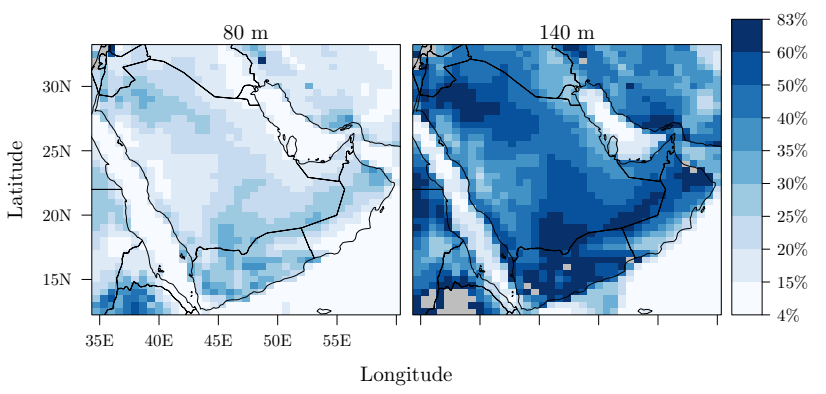

Figure 9: Changes of availability (fig. 8) at $80 \mathrm{~m}$ and $140 \mathrm{~m}$ from those at $50 \mathrm{~m}$ AGL. Large extreme values beyond the 98 percentile in the spatial domain are masked in grey. The color scale is uniform except for values beyond $40 \%$ and below $15 \%$.

\section{3.3.2. Persistence}

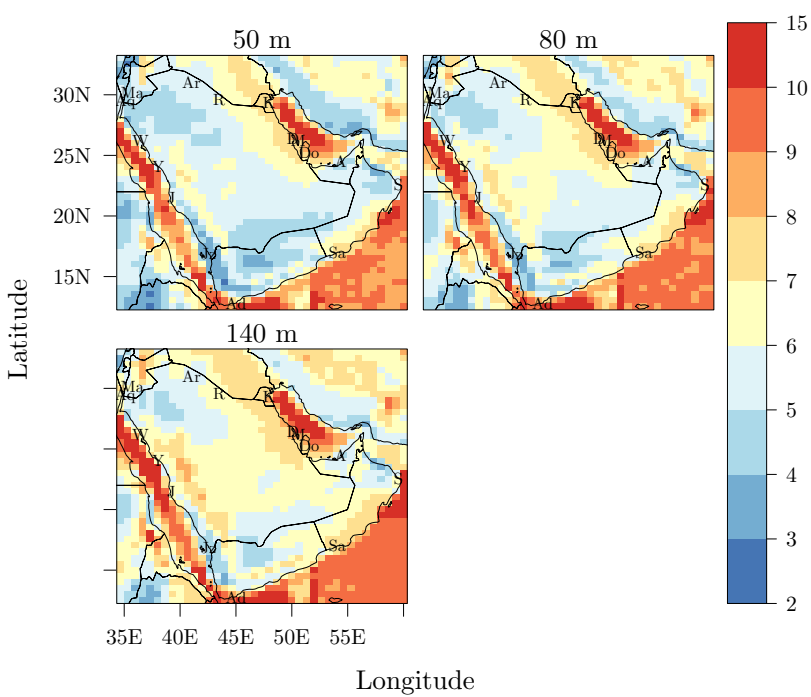

Figure 10: Median length of wind episode (h) computed at $50 \mathrm{~m}$ $80 \mathrm{~m}$, and $140 \mathrm{~m} \mathrm{AGL}$ using the wind fields reconstructed from the MERRA data. The color scale is uniform except for values beyond $10 \mathrm{~h}$. Selected locations of prior studies (table A.1) are shown.

Median episode length (fig. 10) measures the persistence of the wind resource, which indicates persistent up-time of energy production at a specific location. In Regime I, MEL is eight hours in the western mountains of Saudi Arabia, central Jordan, and the southern coast of Oman. It indicates that the wind resource at these locations is persistent for at least eight consecutive hours during half of the record period. At the tip of Yemen at the Gulf of Aden, the MEL is 14 hours. Moderate MEL above five hours by the coast of the 
Gulf of Aqaba is noticed. Areas with moderate wind 666 speed near the Arabian Gulf such as Kuwait and ${ }_{667}$ eastern Saudi Arabia show a higher persistence of 668 the wind with the MEL of greater than eight hours. 669 Low wind abundance regions exhibit persistence with 670 the MEL of below five hours. The MEL tends to 671 increase with hub height with almost no exceptions 672 (fig. A.6).

\section{Conclusions}

This study provides the first regional assessment of ${ }^{670}$ the abundance, variability, and intermittency of wind resource over the Arabian Peninsula. Employing ${ }_{681}$ the MERRA dataset, the wind field at different hub heights is reconstructed applying similarity theory using the roughness length, friction velocity, and displacement height. The reconstructed wind field spans over three decades with consistent spatial and temporal resolution. The wind power density field enables analysis of various aspects of the large-scale ${ }^{684}$ features of the wind energy resources in the Arabian ${ }^{685}$ Peninsula. The wind resource is also characterized ${ }^{686}$ using metrics of wind variability and persistence. This ${ }^{687}$ work improves upon the earlier comprehensive studies ${ }^{688}$ in providing an areal overview of the wind resource ${ }^{689}$ with higher spatial resolution and metrics of temporal ${ }^{690}$ variations in the wind. Previously unrecognized ${ }^{691}$ locations of interest with high wind abundance and low ${ }^{692}$ variability and intermittency have been identified in ${ }^{693}$ this study and confirmed by recent on-site observations [40]. In particular, the western mountains of Saudi ${ }^{69}$ Arabia experience more abundant wind resource than most Red Sea coastal areas. The wind resource is ${ }^{697}$ more variable in coastal areas along the Arabian Gulf than their Red Sea counterparts at a similar latitude. More persistent wind is also found along the coast of ${ }^{698}$ the Arabian Gulf.

This analysis points to the areas previously not recognized. Studies at finer resolutions for these identified 700 areas are necessary to resolve spatial features and local 701 circulations relevant to wind power generation. Our ${ }^{702}$ reconstructed wind field will enable investigations on ${ }_{704}^{703}$ the impact of large-scale circulations on regional wind 705 resources. Effects of the El Niño Southern Oscillation 706 (ENSO) [50] and the North Atlantic Oscillation (NAO) ${ }^{707}$ [51] at various hub heights can be assessed using ${ }_{709}^{708}$ the reconstructed wind fields at different hub heights. 710 The economic viability of wind energy applications 711 at a regional scale can be conducted with higher ${ }^{712}$ spatial and temporal resolution using this dataset ${ }_{714}^{713}$ to provide greater consistency than in prior studies 715
[11, 52-54]. Specifically, wind power production in this region can be modeled in a way similar to those performed in Northern Ireland [55], Great Britain [56], and Sweden [57]. In light of an estimated 25 years turbine lifetime [58], sustainable deployment of wind energy systems in the region requires assessments of the effects of climate change on the regional wind resource using developed approach [59]. A measurecorrelate-predict (MCP) approach can be used to estimate the long-term wind resources at a target site using our reconstructed wind fields in conjunction with short-term wind measurement campaigns [60]. An investigation into the best pattern for wind power aggregation through region-wide interconnection to mitigate intermittency will be a timely and valuable next step towards an optimal integration of large-scale wind energy systems in the Arabian Peninsula [61].

\section{Acknowledgement}

Research reported in this publication was supported by the King Abdullah University of Science and Technology (KAUST) and the Saudi Basic Industries Corporation (SABIC) under grant number $\mathrm{RGC} / 3 / 1815-01$. For computer time, this research used the resources of the Supercomputing Laboratory at King Abdullah University of Science and Technology (KAUST) in Thuwal, Saudi Arabia. MERRA data used in this study have been provided by the Global Modeling and Assimilation Office (GMAO) at NASA Goddard Space Flight Center through the NASA GES DISC online archive. We thank the two anonymous reviewers for their careful reading of our manuscript and their many insightful comments and suggestions.

\section{A. Appendix}

\section{References}

[1] Marvel K, Kravitz B, Caldeira K. Geophysical limits to global wind power. Nature Climate Change 2013;3(2):11821. doi:10.1038/nclimate1683.

[2] Barthelmie RJ, Pryor SC. Potential contribution of wind energy to climate change mitigation. Nature Climate Change 2014;4(8):684-8. doi:10.1038/nclimate2269.

[3] McElroy MB, Lu X, Nielsen CP, Wang Y. Potential for wind-generated electricity in china. Science 2009;325(5946):1378-80. doi:10.1126/science.1175706.

[4] Bryden J, Riahi L, Zissler R. MENA renewables status report. Tech. Rep.; 2013. URL: http: //www.ren21.net/Portals/0/documents/activities/ Regional\%20Reports/MENA_2013_highres.pdf.

[5] El-Katiri L, Fattouh B, Oxford Institute for Energy Studies - A roadmap for renewable energy in the Middle East and North Africa. 2014. ISBN 97819075559091907555900. 


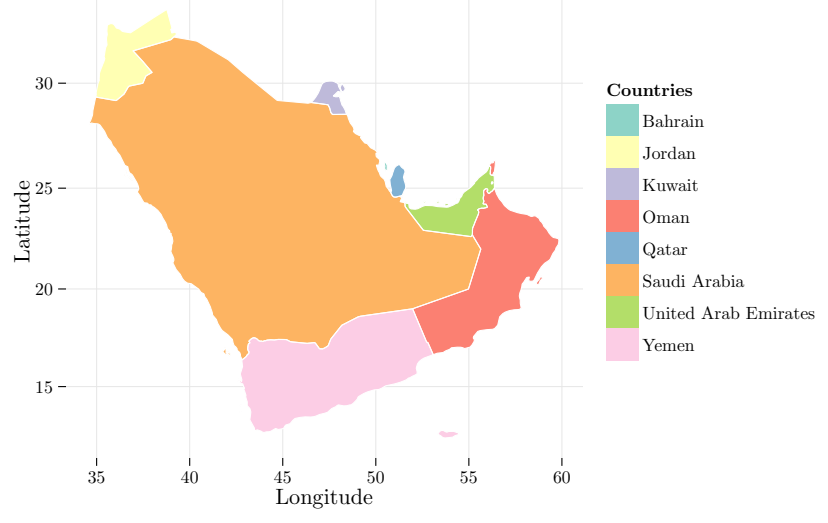

Figure A.1: Country map in the Middle East

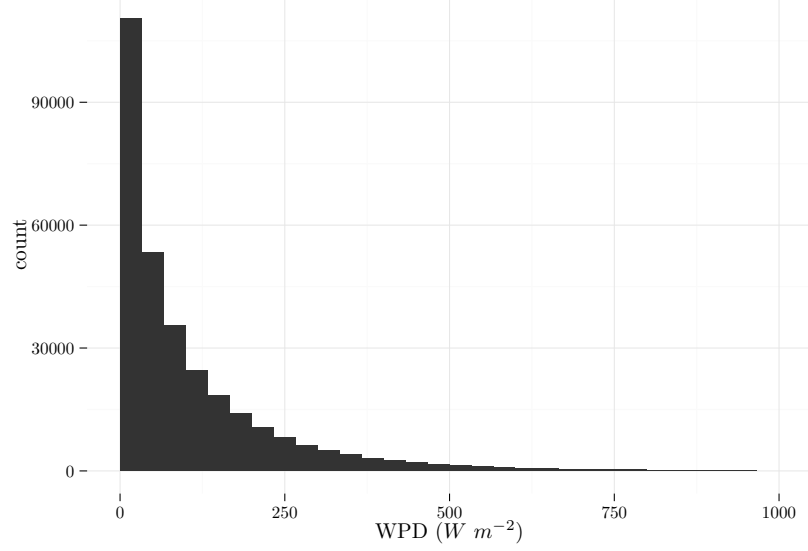

Figure A.2: Illustration of a skewed distribution of WPD at Yanbu

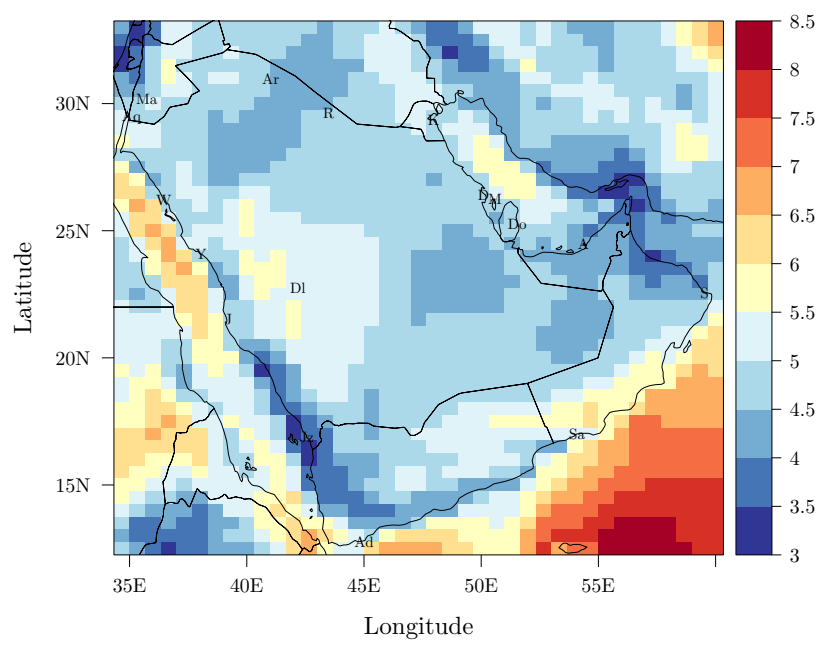

Figure A.3: Average wind speed $\left(\mathrm{m} \mathrm{s}^{-1}\right)$ is computed at $50 \mathrm{~m}$ AGL using the wind fields reconstructed from the MERRA data. Selected locations of prior studies (table A.1) are shown.

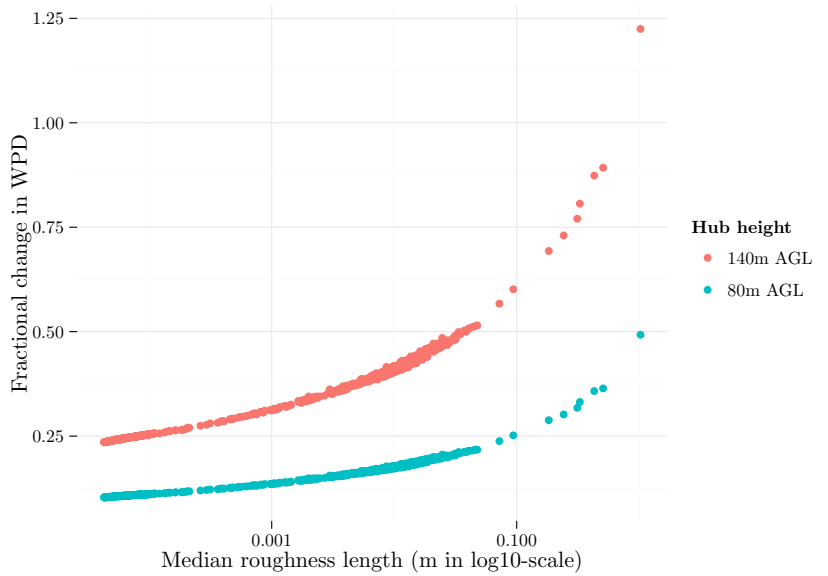

Figure A.4: Fractional change in WPD at $80 \mathrm{~m}$ and $140 \mathrm{~m}$ from $50 \mathrm{~m}$ over temporal median of roughness lengths

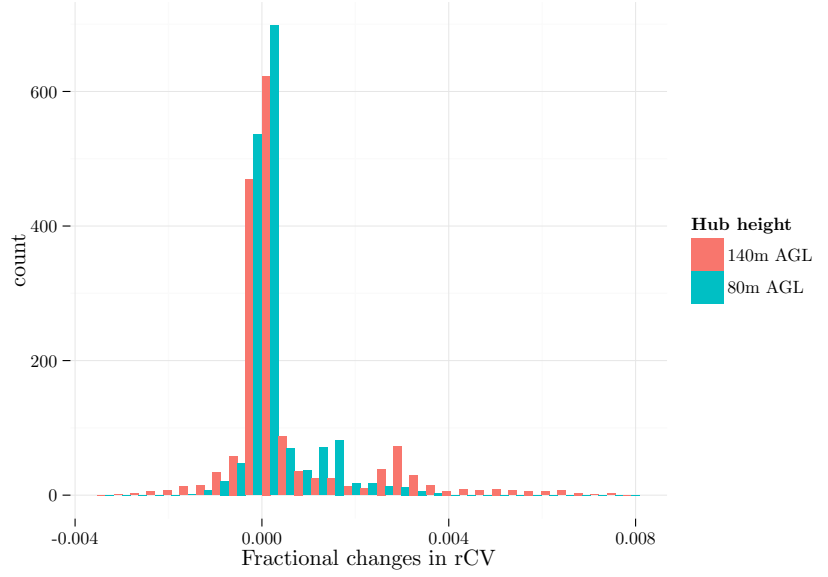

Figure A.5: Distribution of fractional changes in $\mathrm{rCV}$ at $80 \mathrm{~m}$ and $140 \mathrm{~m}$ from $50 \mathrm{~m}$ out of 1638 grid cells

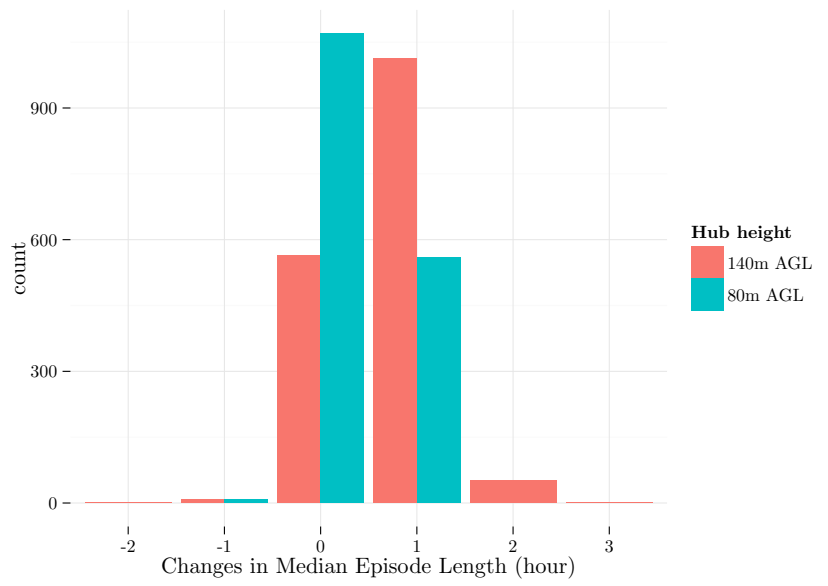

Figure A.6: Distribution of differences in MEL at $80 \mathrm{~m}$ and $140 \mathrm{~m}$ from $50 \mathrm{~m}$ out of 1638 grid cells 


\begin{tabular}{ll}
\hline Mark & Location \\
\hline Ma & Maan \\
Y & Yanbu \\
Ar & Arar \\
R & Rafha \\
D & Dhahran \\
Aq & Aqaba \\
Sa & Salalah \\
W & Al Wajh \\
Jz & Jizan \\
S & Sur \\
Do & Doha \\
M & Manama \\
A & Abu Dhabi \\
Ad & Aden \\
J & Jeddah \\
K & Kuwait \\
Dl & Dhulum \\
\hline
\end{tabular}

Table A.1: Selected locations of prior studies in the region as indicated on the maps.

[6] Smith A, Lott N, Vose R. The integrated surface database: ${ }^{784}$ Recent developments and partnerships. Bulletin of the ${ }^{785}$ American Meteorological Society 2011;92(6):704-8. doi:10. ${ }^{786}$ 1175/2011BAMS3015.1.

[7] Ansari J, Madni IK, Bakhsh H. Saudi arabian wind energy ${ }^{78}$ atlas. Riyadh, Saudi Arabia: KACST 1986;:1-27.

[8] Rehman S, Halawani TO. Statistical characteristics of 790 wind in saudi arabia. Renewable Energy 1994;4(8):949-56. ${ }^{791}$ doi:10.1016/0960-1481 (94)90229-1.

[9] Ucar A, Balo F. Investigation of wind characteristics and ${ }^{793}$ assessment of wind-generation potentiality in uludă̆-bursa, 794 turkey. Applied Energy 2009;86(3):333-9. doi:10.1016/j. ${ }^{795}$ apenergy.2008.05.001

[10] Fyrippis I, Axaopoulos PJ, Panayiotou G. Wind energy ${ }^{797}$ potential assessment in naxos island, greece. Applied ${ }^{798}$ Energy 2010;87(2):577-86. doi:10.1016/j.apenergy. 2009. ${ }^{799}$ 05.031.

[11] Akdă SA, Bagiorgas HS, Mihalakakou G. Use of two- ${ }^{801}$ component weibull mixtures in the analysis of wind 802 speed in the eastern mediterranean. Applied Energy ${ }^{803}$ 2010;87(8):2566-73. doi:10.1016/j.apenergy.2010.02. ${ }^{804}$ 033.

[12] Ohunakin O, Adaramola M, Oyewola O. Wind energy eval- ${ }^{806}$ uation for electricity generation using WECS in seven se- ${ }^{807}$ lected locations in nigeria. Applied Energy 2011;88(9):3197- ${ }^{808}$ 206. doi:10.1016/j. apenergy.2011.03.022.

[13] Jervase JA, Al-Lawati AM. Wind energy potential 810 assessment for the sultanate of oman. Renewable and 811 Sustainable Energy Reviews 2012;16(3):1496-507. doi:10. ${ }^{812}$ 1016/j.rser.2011.12.011.

[14] Al-Yahyai S, Charabi Y, Al-Badi A, Gastli A. Nested ${ }^{814}$ ensemble NWP approach for wind energy assessment. ${ }^{815}$ Renewable Energy 2012;37(1):150-60. doi:10.1016/j. ${ }^{816}$ renene.2011.06.014

[15] Al-Yahyai S, Charabi Y. Assessment of large-scale wind ${ }^{818}$ energy potential in the emerging city of duqm (oman). ${ }^{819}$ Renewable and Sustainable Energy Reviews 2015;47:438 820 47. doi:10.1016/j.rser.2015.03.024.

[16] Charabi Y, Al-Yahyai S, Gastli A. Evaluation of NWP per- ${ }^{822}$ formance for wind energy resource assessment in oman. Re- ${ }^{823}$ newable and Sustainable Energy Reviews 2011;15(3):154555. doi:10.1016/j.rser.2010.11.055.

[17] Kirby B, Ela E, Milligan M. Chapter 7 - analyzing the impact of variable energy resources on power system reserves. In: Jones LE, editor. Renewable Energy Integration. Boston: Academic Press. ISBN 978-0-12-407910-6; 2014, p. $83-99$.

[18] Kwon SD. Uncertainty analysis of wind energy potential assessment. Applied Energy 2010;87(3):856-65. doi:10. 1016/j . apenergy . 2009.08.038.

[19] Lin J, Sun Yz, Cheng L, Gao Wz. Assessment of the power reduction of wind farms under extreme wind condition by a high resolution simulation model. Applied Energy 2012;96:21-32. doi:10.1016/j . apenergy . 2011.10.028.

[20] Jung S, Arda Vanli O, Kwon SD. Wind energy potential assessment considering the uncertainties due to limited data. Applied Energy 2013;102:1492-503. doi:10.1016/j . apenergy.2012.09.011.

[21] Rehman S, Ahmad A. Assessment of wind energy potential for coastal locations of the kingdom of saudi arabia. Energy 2004;29(8):1105-15. doi:10.1016/j . energy . 2004.02.026.

[22] Rehman S, Halawani TO, Husain T. Weibull parameters for wind speed distribution in saudi arabia. Solar Energy 1994;53(6):473-9. doi:10.1016/0038-092X (94) 90126-M.

[23] Rehman S, Mahbub Alam AM, Meyer JP, Al-Hadhrami LM. Wind speed characteristics and resource assessment using weibull parameters. International Journal of Green Energy 2012;9(8):800-14. doi:10.1080/15435075.2011. 641700 .

[24] Jowder FAL. Wind power analysis and site matching of wind turbine generators in kingdom of bahrain. Applied Energy 2009;86(4):538-45. doi:10.1016/j . apenergy. 2008. 08.006 .

[25] Ouarda TBMJ, Charron C, Shin JY, Marpu PR, AlMandoos AH, Al-Tamimi MH, et al. Probability distributions of wind speed in the UAE. Energy Conversion and Management 2015;93:414-34. doi:10.1016/j.enconman. 2015.01 .036 .

[26] Gunturu UB, Schlosser CA. Characterization of wind power resource in the united states. Atmos Chem Phys 2012;12(20):9687-702. doi:10.5194/acp-12-9687-2012.

[27] Cosseron A, Gunturu UB, Schlosser CA. Characterization of the wind power resource in europe and its intermittency. Energy Procedia 2013;40:58-66. doi:10.1016/j.egypro. 2013.08.008.

[28] Fant C, Gunturu B, Schlosser A. Characterizing wind power resource reliability in southern africa. Applied Energy ????;doi:10.1016/j .apenergy .2015.08.069.

[29] Hallgren W, Gunturu UB, Schlosser A. The potential wind power resource in australia: A new perspective. PLoS ONE 2014;9(7):e99608. doi:10.1371/journal pone.0099608.

[30] Rienecker MM, Suarez MJ, Gelaro R, Todling R, Bacmeister J, Liu E, et al. MERRA: NASA's modern-era retrospective analysis for research and applications. Journal of Climate 2011;24(14):3624-48. doi:10.1175/JCLI-D-1100015.1.

[31] Emeis S. Wind Energy Meteorology Atmospheric Physics for Wind Power Generation. Berlin, Heidelberg: Springer; 2013. ISBN 97836423052383642305237.

[32] Dyer AJ, Hicks BB. Flux-gradient relationships in the constant flux layer. Quarterly Journal of the Royal Meteorological Society 1970;96(410):715-21. doi:10.1002/ qj . 49709641012.

[33] Archer CL. Spatial and temporal distributions of u.s. winds and wind power at $80 \mathrm{~m}$ derived from measurements. Journal of Geophysical Research 2003;108(D9). doi:10. 1029/2002JD002076.

[34] Rehman S. Wind energy resources assessment for yanbo, 
saudi arabia. Energy Conversion and Management 892 2004;45(13-14):2019-32. doi:10.1016/j.enconman.2003. 893 11.009 .

[35] Firtın E, Güler Ö, Akdă̆ SA. Investigation of wind 895 shear coefficients and their effect on electrical energy 896 generation. Applied Energy 2011;88(11):4097-105. doi:10. 897 1016/j. apenergy . 2011.05.025.

[36] Short W, Sullivan P. Regional energy deployment system 899 (ReEDS). Tech. Rep. NREL/TP-6A20-46534; National 900 Renewable Energy Laboratory; 2011.

[37] Cassola F, Burlando M. Wind speed and wind energy 902 forecast through kalman filtering of numerical weather 903 prediction model output. Applied Energy 2012;99(0):154- 904 66. doi:10.1016/j.apenergy.2012.03.054.

[38] Draxl C, Clifton A, Hodge BM, McCaa J. The wind 906 integration national dataset (WIND) toolkit. Applied 907 Energy 2015;151:355-66. doi:10.1016/j.apenergy.2015. 908 03.121

[39] King Abdullah City for Atomic and Renewable Energy 910 (K.A.CARE) . Renewable resource atlas. 2015. URL: 911 https://rratlas.kacare.gov.sa.

[40] Al-Abbadi NM. Wind energy resource assessment 913 for five locations in saudi arabia. Renewable Energy 914 2005;30(10):1489-99. doi:10.1016/j.renene.2004.11.013. 915

[41] Rehman S. Prospects of wind farm development in saudi 916 arabia. Renewable Energy 2005;30(3):447-63. doi:10.1016/ 917 j.renene.2004.04.008.

[42] AL-Yahyai S, Charabi Y, Gastli A, Al-Alawi S. Assessment 919 of wind energy potential locations in oman using data 920 from existing weather stations. Renewable and Sustainable 921 Energy Reviews 2010;14(5):1428-36. doi:10.1016/j.rser. 922 2010.01 .008$.

[43] Algifri AH. Wind energy potential in aden-yemen. Re- 924 newable Energy 1998;13(2):255-60. doi:10.1016/S0960- 925 1481 (97) 00069-4.

[44] Bataineh KM, Dalalah D. Assessment of wind energy 927 potential for selected areas in jordan. Renewable Energy 928 2013;59:75-81. doi:10.1016/j.renene.2013.03.034. 929

[45] Al-Nassar W, Alhajraf S, Al-Enizi A, Al-Awadhi L. Potential wind power generation in the state of kuwait. Renewable Energy 2005;30(14):2149-61. doi:10.1016/j . renene.2005.01.002.

[46] Schwartz MN, Elliott DL. Wind shear characteristics at central plains tall towers. Tech. Rep.; National Renewable Energy Laboratory; 2006. URL: http://www.mapcruzin. com/wind-power-publications/wind-issues/40019.pdf.

[47] Vestas . Mesoscale model description. Tech. Rep.; 2013. URL: http://rratlas.kacare.gov.sa/RRMMDataPortal/ Content/pdf/121019mazag_MesoscaleModelDescription. pdf.

[48] International Renewable Energy Agency . Global atlas for renewable energy 2.0. 2015. URL: http://irena.masdar.ac. ae.

[49] 3TIER Inc. . 3tier global wind dataset annual mean validation. Tech. Rep.; 3TIER Inc.; 2009. URL: http:// www.3tier.com/static/ttcms/us/documents/publications/ validations/3TIER WP FL gbl wind validation.pdf.

[50] Klink K. Atmospheric circulation effects on wind speed variability at turbine height. Journal of Applied Meteorology and Climatology 2007;46(4):445-56. doi:10.1175/ JAM2466. 1.

[51] Cullen HM, Kaplan A, Arkin PA, deMenocal PB. Impact of the north atlantic oscillation on middle eastern climate and streamflow. Climatic Change 2002;55(3):315-38. doi:10. 1023/A : 1020518305517

[52] Shawon MJ, El Chaar L, Lamont LA. Overview of wind energy and its cost in the middle east. Sustainable Energy Technologies and Assessments 2013;2:1-11. doi:10.1016/j . seta.2013.01.002.

[53] Rehman S, Halawani TO, Mohandes M. Wind power cost assessment at twenty locations in the kingdom of saudi arabia. Renewable Energy 2003;28(4):573-83. doi:10.1016/ S0960-1481 (02) 00063-0.

[54] Marafia AH, Ashour HA. Economics of off-shore/onshore wind energy systems in qatar. Renewable Energy 2003;28(12):1953-63. doi:10.1016/S0960-1481(03)000600 .

[55] Kubik ML, Brayshaw DJ, Coker PJ, Barlow JF. Exploring the role of reanalysis data in simulating regional wind generation variability over northern ireland. Renewable Energy 2013;57:558-61. doi:10.1016/j.renene.2013.02. 012.

[56] Cannon DJ, Brayshaw DJ, Methven J, Coker PJ, Lenaghan D. Using reanalysis data to quantify extreme wind power generation statistics: A 33 year case study in great britain. Renewable Energy 2015;75:767-78. doi:10.1016/j.renene. 2014.10.024

[57] Olauson J, Bergkvist M. Modelling the swedish wind power production using MERRA reanalysis data. Renewable Energy 2015;76:717-25. doi:10.1016/j.renene.2014.11. 085.

[58] Staffell I, Green R. How does wind farm performance decline with age? Renewable Energy 2014;66:775-86. doi:10.1016/j.renene. 2013.10.041.

[59] Fant C, Adam Schlosser C, Strzepek K. The impact of climate change on wind and solar resources in southern africa. Applied Energy 2015;doi:10.1016/j.apenergy. 2015.03.042

[60] Carta JA, Cabrera P, Matías JM, Castellano F. Comparison of feature selection methods using ANNs in MCP-wind speed methods. a case study. Applied Energy 2015;158:490507. doi:10.1016/j.apenergy. 2015.08.102.

[61] Gunturu UB, Schlosser CA. Behavior of the aggregate wind resource in the ISO regions in the united states. Applied Energy 2015;144:175-81. doi:10.1016/j.apenergy. 2015. 02.013 